\title{
A Study on the Development Direction of the Online-based Summative Assessment System
}

\section{온라인 총괄평가 시스템 개발 방향 탐색을 위한 기초연구}

\author{
Eun-Jin Shin ${ }^{1}$, Soo-Cheol Kim² \\ 신은진 ${ }^{1}$, 김수철 ${ }^{2}$ \\ ${ }^{1}$ Postgraduate Student, Department of Education, Kyungpook National University, Korea, \\ eunjin7804@gmail.com \\ ${ }^{2}$ Professor, Department of Mathematics Education, Daegu Catholic University, Korea, \\ sck0211@gmail.com
}

Corresponding author: Soo-Cheol Kim

\begin{abstract}
As the 2015 revised curriculum is activated at all school levels, schools are applying continuous assessment and use of various assessment methods to aid the teaching-learning process. However, summative assessment does not stand out due to the perception that it is a result-oriented assessment. Therefore, with a focus on the role of summative assessment in the assessment paradigm for learning, in this study, assessment using an online summative assessment system was proposed. Recently, the Ministry of Education is preparing a plan to introduce and implement the computer-based assessment of academic achievement (eNAEA), the representative overall assessment of Korea. In this context, summative evaluation by school unit was also explored as basic data for online development. Therefore, in this study, the direction for the development of an online summative assessment system that can increase the effectiveness based on the role of summative assessment in the changing assessment paradigm was explored. To this end, based on the current status of the online and domestic online assessment systems and the theoretical and methodical exploration for establishing the online summative assessment system, the researchers discussed the assessment of the online summative assessment system and development plans in theoretical, technical and functional aspects.
\end{abstract}

Keywords: Assessment System, Online-based Assessment, Summartive Assessment, Process-based Assessment

요약: 2015 개정 교육과정이 모든 학교급에 활성화됨에 따라 학교에서는 학습에 도움을 주고 자 교수-학습 중 지속적인 평가시행 및 다양한 평가 방법 활용을 적용하고 있다. 그러나 총괄 평가는 결과 중심적인 평가라는 인식으로 인해 두각을 받지 못하는 상황이다. 이에 학습을 위한 평가 패러다임에서의 총괄평가 역할에 초점을 두고 본 연구에서는 온라인 총괄평가 시 스템을 활용한 평가 시행을 제안하였다. 최근 교육부에서는 우리나라 대표적인 총괄평가인 학업성취도 평가를 컴퓨터 기반 학업성취도 평가(eNAEA)로 도입 및 시행 방안을 마련하고 있 다. 이러한 맥락에서 학교 단위별 총괄평가 또한 온라인으로 개발하는 방안에 대한 기초자료 로 탐색하였다. 따라서 본 연구에서는 변화하는 평가 패러다임에서의 총괄평가의 역할을 기 초로 효과성을 증대시킬 수 있는 온라인 총괄평가 시스템 개발을 위한 방향성을 탐색하였다.

Received: June 02, 2021; ${ }^{\text {st }}$ Review Result: July 18, 2021; $2^{\text {nd }}$ Review Result: September 03, 2021

Accepted: October 31, 2021 
이를 위해 국내외 온라인 평가 시스템 현황과 온라인 총괄평가 시스템 구축을 위한 이론적, 방법적 탐색을 토대로 온라인 총괄평가 시스템의 평가 및 이론적, 기술 및 기능적 측면에서 의 발전 방안에 논의하였다.

핵심어: 평가 시스템, 온라인 기반 평가, 총괄평가, 과정 중심 평가

\section{1. 서론}

지식 정보화 사회에서는 인간을 포함한 사회 모든 분야에 계속된 변화와 혁신을 요구한다. 이러한 요구에 따라 교육 현장에서도 다양한 변화가 시도되고 있다. 최근에는 국내의 몇몇 학교들이 다양한 스마트 기기와 최첨단 시설 및 장비를 교육에 접목하려고 시도하고 있으며, 온라인 기반의 수업 및 평가 실시, 학습 진도 관리, 개인 맞춤형 피드백 제공, 가상 공간 및 현실을 활용한 체험 활동 등을 구현할 수 있는 스마트 교실 구축에 많은 관심을 보이고 있다. 이러한 정보화 및 온라인 기반에서의 교육은 학습자들에게 지식 정보사회에서 요구하는 다양한 경험을 간접적으로 접할 기회를 제공한다. 따라서 이러한 변화에 대처하기 위해서는 학습환경, 교육과정, 교수학습 방법 및 평가 등에 대한 새로운 시도와 방향 설정이 필요하다.

한편 2015 개정 교육과정이 모든 학교급에 활성화됨에 따라 교육부에서는 과정 중심 평가 강화와 평가를 통해 학생의 학업능력 신장에 집중하는 학습을 위한 평가의 중요성을 강조하며 시행을 촉구하였다. 즉 평가의 방법이 기존에 지식을 얼마나 알고 있는가에 관한 결과 지향적 평가에서 학습자에게 학습을 촉진해 주는 학습 지향적 평가로의 변화함을 의미한다. 반면 총괄평가는 학습에 대한 결과 지향적 평가라는 인식으로 인해 2015 개정 교육과정 상황에서는 두각을 받지 못하는 실정이다. 이에 온라인 총괄평가 시스템은 상대적으로 소외된 총괄평가에 인식을 개선하는 방안으로 작용할 수 있다. 총괄평가를 온라인 평가 시스템으로 전환하여 시행한다면 대부분 학교에서 차용하고 있는 OMR 카드 인식 및 채점에 대한 문제점을 보완할 수 있어 교사들의 업무 부담을 줄일 수 있으며, 학습자의 평가 응답을 분석하여 개별화된 피드백 및 학습자료를 제공할 수 있는 학습 지원으로 이어질 수 있다. 따라서 과정 중심 평가 상황에서 효과적인 총괄평가를 지원할 수 있는 온라인 평가 도입 및 체제에 대한 논의가 필요하다.

이러한 상황을 반영하여 우리나라에서 대표적인 총괄평가로 볼 수 있는 학업성취도 평가가 컴퓨터 기반으로 변화하고 있다. 최근 교육부에서는 컴퓨터 기반 평가 관련 국제 동향, 개정된 교육과정에서 강조하는 역량 평가 구현의 필요성과 관련하여 2015 개정 교육과정의 교과 역량을 반영한 컴퓨터 기반 학업성취도 평가(electronic National Assessment of Educational Achievement: 이하 eNAEA)의 도입 및 시행 방안을 마련하고 있다[1]. 평가의 형태가 기존 지필 형태에서 컴퓨터 및 온라인 기반으로 변화하고 있는 패러다임에서 컴퓨터 기반 국가수준 학업성취도 평가는 좋은 사례이며, 학교 현장에서 이루어지는 총괄평가 또한 이러한 변화 요구에 직면한 것으로 해석할 수 있다. 특히 우리나라뿐 아니라 전 세계적으로 COVID-19라는 예상치 못한 상황 속에서 지구촌의 17억이 넘는 학생들이 영향을 받으며 학업 중단 위기를 맞이하였다[2]. COVID-19 이슈는 교육 체제 전반에 걸쳐 대대적인 변화와 유연성이 필요함을 시사하였고, 대면 교육에서 
비대면 교육 체계 개발 및 발전의 변화를 모색해야 함이 더욱 강조되었다.

지식정보화사회 속에서의 실현되는 교육, 컴퓨터 기반으로의 학업성취도 평가 시행, 온라인 및 비대면 교육 확산 등과 같은 이슈들로 인해 최근 학교 현장에서는 Z00M, Google 클래스룸, EBS온라인 클래스, e학습터 등 다양한 온라인 및 원격수업으로 이용하는 플랫폼을 교육에 활용하는 추세이다. 이러한 플랫폼들을 이용하여 화상수업, 쪽지 등을 이용한 소통, 게시판을 이용한 학습자료 공유 및 과제 제공, 퀴즈를 이용한 형성평가 등 학교 현장 및 수업 상황에서 나타나는 요소들을 온라인상에서 구현하고 있다. 실제 학교 현장에서 일어나는 대부분 교육적 상황들이 온라인에서도 잘 구현되고 있지만, 학습과제 수행의 결과를 평가하여 학업성적을 판단하고 이에 관한 결과를 통보하는 총괄평가의 경우 온라인 상황에서는 이루어지고 있지 않다.

종합적으로 본 연구에서는 과정 중심 평가 패러다임에서의 총괄평가의 역할을 기초로 평가의 효과성을 증대시킬 수 있는 온라인 총괄평가 시스템 개발 방향성을 탐색하고자 한다.

\section{2. 온라인 평가 시스템 운영 현황}

\section{1 국내 온라인 평가 시스템 현황}

국내 온라인 평가 시스템은 공공성 측면에서 크게 국가 및 공공기관이 주관하는 형태, 민간기업이 공공 참여하는 형태, 교육사업을 시행하는 사기업이 참여하는 형태로 나눌 수 있다. 이 중에서 국가 및 공공기관이 주관하는 총괄평가의 맥락에서 탐색할 수 있는 $\mathrm{eNAEA}$ 에 중점을 두어 현황을 파악하고자 한다. 교육부가 역량 중심, 컴퓨터 기반 평가, 정의적 특성 반영, 활용도 제고 등의 내용을 담은 학업성취도 평가 개선 방안을 발표하면서 2021년 지필 평가와 컴퓨터 기반 평가의 병행과 2022년 컴퓨터 기반 학업성취도 평가의 전면 도입을 계획하였다. 이에 $\mathrm{eNAEA} \mathrm{도입을} \mathrm{위한} \mathrm{검사} \mathrm{설계} \mathrm{방안}$ 연구[3]와 출제 방안 연구[1]를 통해 eNAEA를 성공적으로 대응하고자 노력하고 있다. 2022년 eNAEA 설계안[3]을 제시하면 [표 1]과 같다. 제시한 바와 같이 컴퓨터 기반 평가 설계를 적용하게 되면 학교 현장에서의 유연한 시행을 위한 일정 조율이 가능해지고, 평가 시행 후 평가 결과 제공 시기를 앞당기는 효과가 있다[3].

[표 1] eNAEA 시행방안

[Table 1] eNAEA Implementation Plan

\begin{tabular}{|c|c|c|}
\hline 구분 & 현행 지필 평가 & eNAEA \\
\hline 평가 교과 & $\begin{array}{l}\text { - 중3: 국, 수, 영, 사, 과 } \\
\text { - 고2: 국, 수, 영 }\end{array}$ & - 현행 지필 평가와 동일 \\
\hline 표집 규모 & $\begin{array}{l}\text { - 전체의 } 3 \% \text { (약 } 12,000 \text { 명) } \\
\text { - 표집학교당 } 2 \text { 학급 }\end{array}$ & - 현행 지필 평가와 동일 \\
\hline 검사 유형 & $\begin{array}{l}\text { - 4종(가 라) } \\
\text { - '가' 형만 공개 }\end{array}$ & $\begin{array}{l}\text { - 5종(가 마) } \\
\text { - 모든 유형 비공개 } \\
\text { - 성취수준별 대표 문항 예시 공개 }\end{array}$ \\
\hline 점수 산출 & - 고전검사이론 적용 & - 문항반응이론과 고전검사이론 적용 \\
\hline
\end{tabular}




\begin{tabular}{|c|c|c|}
\hline 결과 제공 시기 & - 평가 시행 후 2개월 후 & $\begin{array}{l}\text { - 서답형 문항을 제외한 결과는 평가 시 } \\
\text { 행 후 } 2 \text { 주 내 } \\
\text { - 서답형 문항 포함 최종 결과는 채점 완 } \\
\text { 료 후 제공 예정 }\end{array}$ \\
\hline 시행기간 & $\begin{array}{l}\text { - } 6 \text { 월 셋째 주(1일) } \\
\text { - 모든 표집학교 동일 시행 }\end{array}$ & $\begin{array}{l}\text { - } 6 \text { 월 셋째 주(5일) } \\
\text { - 표집학교가 시행 일자 선택 }\end{array}$ \\
\hline 검사 유형 분배 & $\begin{array}{l}\text { - 표집학교 } 1 \text { 개 학급은 '가' 형 나머지 } \\
1 \text { 개 학급은 '나' '라' 형 가운데 임 } \\
\text { 의 분배 }\end{array}$ & - 시행 일자에 따라 검사 유형 분배 \\
\hline
\end{tabular}

학업성취도 평가가 지필 평가에서 컴퓨터 기반 평가로 전환되는 것은 평가 방식에서 매체의 변화와 출제 과정에서 문항 개발의 변화가 동시에 요구되었다. 먼저 시스템 설계는 출제, 채점, 결과 보고를 관리할 수 있도록 설계되고 있다. 출제 시스템도 지필 평가 체제와 유사하게 출제팀과 검토 및 평가팀이 구분되어 문항 개발이 이루어졌다. 출제팀은 출제팀장, 교과별 출제기획위원, 출제위원으로 구성되며, 검토 및 평가팀은 평가팀장, 교과별 검토기획위원, 검토위원으로 구성되었다. 다음으로 문항 개발은 지필 평가 방식의 문항 개발 절차를 분석하여 컴퓨터 기반 평가에서는 어떠한 절차들이 개선되고 추가되어야 하는지에 중점을 두어 진행되고 있다.

기존 지필 평가와 달리 컴퓨터 기반의 eNAEA는 다양한 문항 유형을 적용할 수 있다는 장점이 있다. 컴퓨터 기반에서 활용 가능한 문항을 기술공학적 기능 활용 문항으로 볼 수 있으며, 이러한 기술공학적 활용 문항 특성은 일곱 개의 차원에서 그 특성을 분석하였다[4]. 기술공학적 기능 활용 문항은 첫째, 평가 구조(assessment structre), 둘째, 응답 행위(response action), 셋째, 미디어 포함 여부(media inclusion), 넷째, 상호작용 수준(interactivity), 다섯째, 복잡성(complexity), 여섯째, 실제성(fidelity), 일곱째, 채점 방법(scoring method)의 일곱 가지 차원에서 기술공학적 특성이 있다. 이러한 7 가지 차원은 컴퓨터 기반 평가에서 혁신적인 문항이 무엇을 지향해야 하는가에 대한 질문에 답을 주며, 문항 유형을 설정하는 데 참조가 된다[1]. 따라서 온라인 총괄평가 시스템 또한 시스템 설계와 문항 개발 두 가지 측면을 신중히 고려하여 개발하되, 과정 중심 평가에서의 총괄평가의 목적과 기술공학적으로 구현할 수 있고 허용할 수 있는 수준, 시행 방식 등을 검토하여 그에 맞는 평가 시스템 개발을 위한 절차를 설정할 필요가 있다.

\section{2 국외 온라인 평가 시스템 현황}

국외 온라인 평가 시스템들은 $\mathrm{eNAEA}$ 와 같이 기존 지필 평가가 온라인 평가 시스템으로 전환되거나 기존 온라인 평가 시스템에 추가 및 변경이 되는 사례가 대부분이었다. 이는 검사 매체와 도구가 진화하면서 컴퓨터를 활용한 출제와 채점 및 관리를 비롯한 전반적인 검사가 자동화된 시스템으로 운영되는 사례가 증가하였기 때문이다. 국외에서 제1세대 컴퓨터 이용검사로 볼 수 있는 지필 평가에서 온라인 평가 시스템으로 전환된 사례는 [표 2]에 제시되었다[5]. 이 경우 단순히 평가 방법이 종이에서 온라인으로 전환된 사례들로 지필 평가와 같은 내용 및 구성이 온라인 평가 시스템에 입력되어 평가가 수행되는 방식이었다. 
[표 2] 지필 평가를 온라인 평가시스템으로 전환한 평가종류

[Table 2] Types of Evaluation that Converted Paper-based Evaluation to an Online Evaluation ystem

\begin{tabular}{|c|c|}
\hline 평가 명칭 & 평가 내용 \\
\hline ePIRLS & $\begin{array}{l}\text { - 교과: 어학, ICT } \\
\text { - 학생들의 읽기능력, 이해능력 } \\
\text { - 인터넷 사용법 } \\
\text { - 읽기능력, 이해능력, 컴퓨터 사용법 }\end{array}$ \\
\hline eTIMMS & $\begin{array}{l}\text { - 교과: 수학, 과학 } \\
\text { - 학생들의 배경지식을 기반으로 한 수학, 과학 문제 }\end{array}$ \\
\hline PARCC & $\begin{array}{l}\text { - 교과: 수학, 어학 } \\
\text { - 영어능력, 영어문학영역 능력, 수학능력 }\end{array}$ \\
\hline TOPCIT & $\begin{array}{l}\text { - 교과: ICT } \\
\text { - IT 관련 지식, 기술, 태도 } \\
\text { - 실무에서 요구하는 다양한 문제해결력 } \\
\text { - 소프트웨어 개발능력, 데이터베이스 구축 운영능력, 네트워크와 보안 이해 및 활용능력, } \\
\text { IT비즈니스 이해능력, 테크니컬 커뮤니케이션 능력, 프로젝트 관리능력 }\end{array}$ \\
\hline NAP ICT Literacy & $\begin{array}{l}\text { - 교과: 수학, 과학, 어학, ICT } \\
\text { - 읽기 쓰기, 철자, 수리, 과학, 시민윤리 } \\
\text { - ICT능력, 직업교육 } \\
\text { - NAP ICT Literacy의 문항 모두 수행형, 컴퓨터로 진행 }\end{array}$ \\
\hline ATC21S & $\begin{array}{l}\text { • 교과: ICT } \\
\text { - 21세기 사회에서 필요로 하는 커뮤니케이션 능력, 협업능력, 문제해결력, ICT 능력 }\end{array}$ \\
\hline ICILS & $\begin{array}{l}\text { - 교과: ICT } \\
\text { - 컴퓨터 사용법 } \\
\text { - 정보접근 및 가치판단 방법 } \\
\text { - 컴퓨터 사용을 위해 데이터가 저장되는 과정 }\end{array}$ \\
\hline $\begin{array}{l}\text { 베브라스 컴퓨팅 } \\
\text { 챌린지 }\end{array}$ & $\begin{array}{l}\text { - 교과: ICT } \\
\text { - 정보과학 분야: 알고리즘과 프로그래밍, 자료 분석과 자료 표현, 컴퓨팅 시스템의 구성과 } \\
\text { 동작원리 등 } \\
\text { - 컴퓨팅 사고력 요소: 문제 분석, 핵심요소 추출, 문제 분해, 모델링, 절차 구성, 패턴 인 } \\
\text { 식 }\end{array}$ \\
\hline
\end{tabular}

2세대부터 진행되는 컴퓨터화 검사는 피험자 개인의 능력 수준에 맞는 문항을 선택적으로 제시함으로써 측정의 오차를 줄일 수 있고, 평가 결과를 통해 학습으로 피드백된다는 점에서 학습을 지원하는 교육적 함의가 크다. 2세대 이후의 컴퓨터화 검사의 사례[5]를 [표 3]에 제시하였으며, 제시된 평가 도구들은 학습 과정에서 학습자가 보인 여러 반응을 평가하고, 학습과 연계하여 학습자 개인 맞춤형 학습 및 평가에 대한 피드백을 제공한다는 특징이 있었다.

1 세대 컴퓨터화 평가 시스템으로부터 꾸준히 발전해 온 국외 온라인 평가 시스템의 사례와 같이 이들은 장기간에 걸쳐 지필 평가를 컴퓨터 및 온라인 기반 평가로 전환하였으며, 지필 평가로 구현하기 어려웠던 평가 내용과 형식을 컴퓨터 매체와 온라인 기반으로 상호작용하여 실현해왔다. 따라서 온라인 총괄평가 시스템 개발 방향에서도 매체 전환 및 문항 개발 및 구성 등을 면밀하게 살펴볼 필요가 있다. 
[표 3] 2세대 이상 컴퓨터화 평가 시스템의 평가목적 및 특징

[Table 3] Assessment Purpose and Characteristics of the Upper 2nd Generation Computerized Assessment System

평가 도구

PISA

협력적 문제해결력
평가 목적

둘 이상의 주체가 문제를 해결하기 위한 다 양한 시도를 평가

교육자, 학생 및 학부모에게 의미있고 실용 적인 데이터를 제공
평가 특징

문제해결과정 4단계, 협력적 문제 해결력 3 단계로 범주화하여 구성

교육 및 학습 향상을 위해 디지털 라이브러 리, 선택적 정기검사, 연말평가의 기능으로 구성

듣기, 어휘, 문법, 독해 4 가지 영역을 평가

시나리오 기반 문항을 통해 문제해결과정에 서 다양한 측면의 사고능력 평가

수강 이력 등을 통해 학사과정 동안의 학생 전반에 대한 평가

학생들의 과제를 포함하여 모든 교육 자료를 저장하여 평가

\section{3. 온라인 총괄평가 시스템 구축을 위한 탐색}

\section{1 온라인 기반 총괄평가 시스템 구축을 위한 이론적 탐색}

온라인 기반 총괄평가 시스템 구축의 방향을 설정하기 위해 지필 평가에서 컴퓨터 기반 평가로의 전환과 관련된 선행연구를 바탕으로 온라인 총괄평가 시행의 장단점과 고려해야 할 요소를 탐색하고자 한다. 먼저 온라인 기반 총괄평가의 구현이 어떤 단계의 컴퓨터화 검사로 실시될 것인가를 고려해야 한다. 컴퓨터화 검사는 4세대로 컴퓨터 이용검사, 컴퓨터화 능력적응검사, 연속측정(Continuous measurement: $\mathrm{CM}$ ), 지적측정(Intelligent measurement: IM)으로 구분되었다[6]. 구체적으로 1 세대는 컴퓨터 이용검사로 전통적 지필 평가와 동일한 내용의 검사를 컴퓨터를 이용 및 실시하는 단계이며, 2 세대는 컴퓨터화 능력적응검사로 개별 피험자의 능력에 맞는 문항을 제시하여 응답결과에 적응하는 방식으로 실시하는 단계이다. 3 세대는 연속측정으로 학습 진행에 따른 학생의 변화를 연속적으로 측정하는 단계이다. 마지막 4세대는 지적측정으로 학습자의 인지구조를 분석하고 잘못된 부분을 교정하여 학습의 극대화 실현을 목적으로 하는 고도화된 측정단계이다. 또한 크게 세 가지로 컴퓨터를 이용한 검사 발달 과정은 크게 컴퓨터 보조 검사(Computer-assisted testing), 컴퓨터화된 검사(Computerized testing: CT), 컴퓨터를 이용한 개별적응검사(Computerized adaptive testing: CAT)로도 구분되었다[7]. 컴퓨터 보조 검사는 수능 또는 각종 시험에 OMR 카드를 이용하여 지필식 검사를 실시하고 채점이나 결과분석 및 보고를 컴퓨터를 활용하여 처리하는 현재 가장 많이 이용되고 있는 검사 방법이다. 컴퓨터화된 검사는 검사의 채점 및 결과 분석뿐 아니라 검사 시행에서 종이와 연필 대신 컴퓨터의 모니터와 입력장치(키보드, 마우스 등)를 사용하는 것으로 검사에 필요한 컴퓨터 하드 및 
소프트웨어가 갖추어져 있어야 하며 문제은행이 사전에 구축되어 있어야 한다. 또한 피험자는 컴퓨터를 사용할 수 있는 능력을 갖추고 있어야 한다. 마지막으로 컴퓨터를 이용한 개별적응검사는 문항반응이론의 원리와 컴퓨터 능력을 이용하여 피험자 수준에 적절한 형태의 검사를 개별 맞춤형으로 제공하여 짧은 시간에 적은 수의 문항으로도 측정하는 특성들을 보다 정확하고 효율적으로 측정할 수 있게 하는 검사이다. 이 단계에서는 컴퓨터화된 검사에서 갖춰야 할 요건이 기본적으로 갖춰져 있어야 하며 동시에 피험자는 컴퓨터 문해력을 갖추고 있어야 한다. 이와 같은 컴퓨터를 이용한 검사의 단계와 수준들을 탐색하는 것은 온라인 총괄평가 시스템이 효율적으로 사용되기 위해서 어떠한 단계에서 구현할 것인가와 같은 질문에 대한 해석을 제공해 줄 수 있다[7].

다음으로 온라인 기반으로 총괄평가를 활용하여 얻을 수 있는 장단점이 고려되어야 한다. 여러 선행연구[7-9]에서 언급된 장점을 교사와 학생 두 가지 측면에서 정리되었다. 먼저 교사 측면에서 총괄평가 과정에서 일어나는 시험지 오타 수정 및 OMR 카드 판독 등과 같은 오류를 줄일 수 있고, 문항의 응답 결과뿐 아니라 응답 소요시간 및 순서, 문항 재검토나 수정 여부 등 학생에 대한 다양한 정보를 분석하고 활용할 수 있다. 또한 사진, 동영상, 음성 등의 각종 참고 자료 정보를 포함한 다양한 형태의 문항을 활용할 수 있고, 문항을 효율적으로 수정 및 제작하여 평가에 대한 교사의 업무 경감을 덜 수 있다. 다음으로 학생 측면에서는 대부분 학생들이 비교적 컴퓨터나 스마트 기기에 익숙함으로 별도의 교육 없이 안내 및 지침을 통해 자연스럽게 컴퓨터 기반 검사에 빠르게 적응할 수 있고, 잘못 기재한 답안을 쉽게 수정할 수 있어서 심리적 부담을 덜 수 있으며, 명확하고 상세한 평가 결과 제시를 받음으로써 평가의 피드백 효과를 높일 수 있다.

\section{2 온라인 기반 총괄평가 시행 방법 및 문항 유형 탐색}

온라인 기반 평가는 평가 방법적 측면과 평가 영역적 측면으로 분류할 수 있다. 먼저 온라인 기반에서 사용되는 평가 방법은 비실시간과 실시간 평가 방법으로 구분된다[10]. 먼저 비실시간 평가 방법은 피험자에 의해 입력된 답안을 일괄적으로 채점, 평가가 끝난 후 결과를 알려주는 방법으로 이메일, 게시판, 파일 전송 프로토콜을 이용한 방법이 해당한다. 이러한 평가 방법은 설계가 간단하여 쉽게 활용할 수 있는 장점이 있지만 교사가 계속 확인 작업과 평가 이후 한꺼번에 채점을 해야하는 부담감이 있다. 다음으로 실시간 평가 방법은 실시간 소통을 통해 문제출제와 동시에 답변하는 채팅모드 방법과 온라인을 통하여 미리 출제된 문제에 답변하는 온라인을 이용하는 방법이 있다. 채팅모드 방법은 교사와 학생이 같은 시간에 실시간 소통창을 통해 출제한 문제에 즉시 답변하여 학생의 학습 수준을 즉각적으로 파악하는 방법이다. 이러한 평가 방법은 교사와 학생 일대일로만 평가할 수 있으므로 다수의 학생을 평가하기에는 많은 시간이 소요되어 학교현장에서의 총괄평가로는 부적합한 방법이다. 온라인을 이용한 방법은 교사가 문제를 미리 출제하여 데이터베이스에 저장한 후 학생들이 일정한 시간에 시험을 치도록 하여 그 결과를 시험 종료 즉시 알 수 있도록 하는 방법이다. 비실시간 평가 방법에 비해 설계 알고리즘이 복잡하지만 학생 입장에서 평가 종료 이후 즉각적으로 결과를 실시간으로 확인하여 자신의 학습 수준에 대한 정보를 파악할 수 있다는 점에서 장점이 있다. 
한편, 기존 지필 평가 형태의 총괄평가에서 제한적으로 사용된 문항 유형이 온라인 총괄평가 시스템 상황에서는 다양한 문항 유형으로 확장될 수 있다. 기존 지필 평가에서 교과학습을 평가하기 위한 문항 유형은 크게 두 가지로 나눌 수 있다. 첫째, 객관식 문항으로 네 개 또는 다섯 개의 답이 주어져 물음에 알맞은 하나의 답을 선택하게 하는 선다형이다. 둘째, 주관식 문항으로 주어진 물음에서 요구하는 정확한 특정 답을 작성하게 하는 단답형과 문장 형태로 답을 쓰게 하는 서술형이며 이는 서답형으로 분류된다. 온라인 총괄평가 시스템을 적용하는 상황에서의 문항 유형은 $\mathrm{eNAEA}$ 에서 구성하는 문항 유형과 같이 분류될 수 있다. $\mathrm{eNAEA}$ 는 학생 응답 측면과 자료 탐색 측면의 문항 유형을 제시하였다. 특히 학생 응답 측면은 선택형 범주와 구성형 범주로 나누어 구체적인 문항 유형을 제시하였다. 학생 응답 측면에서의 eNAEA 문항 유형은 크게 선택형 범주와 구성형 범주로 구분되며, 선택형 범주의 문항유형은 선다형, 확장 선택형, 자료 연결형, 순서 배열형으로 구성되며, 구성형 범주의 문항유형은 단답형, 서술형, 수정형, 그래프/그림 완성형으로 구성된다[3].

\section{3 온라인 기반 총괄평가 시스템 개발의 발전 방안}

온라인 총괄평가 시스템은 온라인 기반이라는 특수성 하에 장단점이 있다. 장점은 채점이 쉬워지며, 학생들의 실력을 더 정확하게 확인할 수 있다는 것이고, 단점은 온라인 환경에 적응하지 못하는 교사와 학생이 발생할 수 있으며, 평가 시행 중 시스템 오류 시 혼란을 일으킬 수 있다는 점이었다. 이러한 장단점을 기반으로 온라인 총괄평가 시스템 개발을 위한 이론 및 문항 유형 탐색과 국내외 온라인 평가 시스템의 목적, 특징 및 내용 등을 분석한 결과로 향후 온라인 총괄평가 시스템의 발전 방안은 크게 평가 및 이론적 측면에서의 발전 방안과 기술 및 기능적 측면에서의 발전 방안으로 나누어지며 [표 4]와 같이 제시된다.

[표 4] 온라인 총괄평가 시스템 개발을 위한 발전 방안

[Table 4] Development Plan for the Development of Online Summative Assessment System

\begin{tabular}{|c|c|}
\hline 측면 & 발전 방안 \\
\hline 평가 및 이론적 & $\begin{array}{l}\text { - 총괄평가 결과를 통한 개별 맞춤화 피드백 제공 지향 } \\
\text { - 문항반응이론을 기반으로 컴퓨터 적응형 검사 도구 시행 } \\
\text { - 교육 및 학습 목표 달성 정도 확인과 총괄평가 결과를 최대한 활용할 수 있는 평가 문항 } \\
\text { 제작 } \\
\text { - 다양한 형태의 문항 출제 } \\
\text { - 문제 풀이시간, 문항 풀이 과정 및 순서 제어 } \\
\text { - 온라인 총괄평가 전문성 강화를 위한 교사 연수 프로그램 개발 및 제공 }\end{array}$ \\
\hline 기술 및 기능적 & $\begin{array}{l}\text { - 사용자(교사, 학생) 접근성 및 편의성을 고려한 인터페이스 구축 } \\
\text { - 온라인에서 구현가능한 각종 멀티미디어 데이터를 활용한 다양한 문항 개발 및 평가 방법 } \\
\text { 이 가능하도록 구축 } \\
\text { - 온라인 기반 평가가 시행가능한 최적의 환경 구축을 위한 행정 및 재정적 지원 } \\
\text { - 정확한 데이터 수집과 분석이 가능하도록 구축 } \\
\text { - 학습데이터와 행동데이터 각각 수집 및 학습자 능력 추정 분석 기능 제공 } \\
\text { - 총괄평가 결과 활용성을 극대화할 수 있는 기능 제공: 학생의 평가 결과를 통해 자신의 학 } \\
\text { 습 상태 수준 점검 및 진로 탐색의 기회 활용할 수 있는 기능 탑재 } \\
\text { - 학생 개인별로 전체적인 총괄평가 결과 세부 내용 및 흐름을 파악할 수 있는 개별 리포트 } \\
\text { 와 교사가 평가 결과를 활용할 수 있도록 오답률 분석, 학생 개인별 정답률 분석 등과 같은 } \\
\text { 교사용 리포트 제공 }\end{array}$ \\
\hline
\end{tabular}


[표 4]에서 제안된 바와 같이 온라인 총괄평가 시스템은 학생 개인의 역량 수립 및 강화와 과정 중심 평가가 시행될 수 있도록 평가 이론적 측면에서 발전 방안을 모색해야 한다. 기존 지필 평가는 문항의 출제와 관련된 문항 제작 및 수정, 오류 점검 등과 총괄평가 결과에 따른 학생 피드백 제공 등의 부분에서 제한이 있다. 평가 및 이론적 관점에서의 발전 방안들을 고려할 때, 기존 지필 평가를 뛰어넘어서 온라인 총괄평가 시스템만이 구현할 수 있는 평가 효과성이 더욱 부각될 것으로 예상된다. 또한 온라인 환경을 충분히 활용하여 기술 및 기능적인 측면에서도 문항 출제 및 시험지 구성의 자동화와 목적에 맞는 평가가 시행될 수 있는 온라인 평가 환경 제어, 실시간 원격제어 및 모니터링 활성화, 평가 결과 제공 및 피드백을 위한 세부 기능 탑재 및 고도화 등을 고려해야 한다.

\section{4. 제언}

본 연구의 목적은 최근 비대면과 온라인 교육이 확대되고 있는 시대의 흐름 속에서 역량기반 및 과정 중심 평가 패러다임에서 총괄평가의 역할을 기초로 평가의 효과성을 증대시킬 수 있는 온라인 총괄평가 시스템 개발 방향성을 탐색하는 것이다. 온라인 총괄평가 시스템이 개발되고 활성화될 경우, 교사들의 업무 경감 및 총괄평가를 위한 소요되는 비용과 시간 또한 감소되며, 객관식, 주관식 및 서술형 문제 등 모든 문제 유형을 오류 없이 정확히 채점할 수 있어 학생들의 학습 능력을 정확하게 측정할 수 있을 것으로 판단된다. 본 연구를 통해 온라인 총괄평가 시스템 개발을 위한 시사점 및 제언은 다음과 같다.

첫째, 평가 및 이론적 측면을 고려한 온라인 총괄평가 시스템 개발 및 발전이 필요하다. 총괄평가는 평가에 따른 결과를 즉각적으로 다음 수업에 반영하기는 어렵지만 일정 기간 동안에서의 학습 목표 달성 여부와 종합적인 학습 상태에 결과가 제공되므로 각 학생 학습능력에 따른 개별 맞춤화 피드백 제공이 가능하다. 또한 평가 결과 활용을 통해 학생의 교과 역량 함양 및 향상 정도도 확인할 수 있다. 이를 위해 본 연구에서는 국내와 국외 컴퓨터 및 온라인 기반 평가 사례 및 관련 선행연구 분석을 통해 평가 패러다임 측면을 고려하여 문항 개발 및 검사지 구성 등을 면밀하게 준비해야 하며, 다양한 형태의 문항 제작 및 설명이 포함되도록 해야 함을 확인하였다. 총괄평가가 지닌 다양한 역할을 온라인 기반으로 더욱 확장될 수 있도록 평가 이론적 측면을 고려하는 것이 필요하다. 또한 교사들이 온라인 총괄평가 시스템을 운영하고 이를 제대로 활용할 수 있도록 전문성 강화를 위한 교사 연수 프로그램 개발 및 제공이 요구된다.

둘째, 기술 및 기능적 측면을 고려한 온라인 총괄평가 시스템 개발 및 발전이 필요하다. 기술 및 기능적 측면에서 온라인 총괄평가 시스템 구현하고자 할 때, 총괄평가 목적과 방향에 따라 컴퓨터화 검사의 수준과 단계 설정이 필요하다. 과정 중심 평가와 평가 결과 활용 측면을 고려한다면 적어도 2세대 컴퓨터화 검사 및 컴퓨터화된 검사(CT) 이상 수준으로 설계하는 것이 제안된다. 또한 실제 사용자인 교사와 학생이 온라인 총괄평가 시스템에 높은 접근성과 편의성을 갖도록 인터페이스를 구축해야 한다. 특히 평가 결과를 정확히 수집하고 분석이 가능하도록 설계하는 것이 무엇보다 중요하다. 온라인 총괄평가 시스템이 기존 지필 형태의 총괄평가와 차별성을 두기 위해서는 학습 데이터 뿐 아니라 학생의 행동 데이터를 각각 수집하여 학습자 능력 추정 분석 기능을 제공하도록 하는 것이 필요하다. 또한 총괄평가 결과 활용성을 
극대화하도록 학생 개인별로 다양한 결과 분석 내용이 담긴 학생 개별 리포트를 제작하고 볼 수 있는 기능 설계도 고려된다.

셋째, 온라인 총괄평가 시스템 개발을 위한 환경 조성이 제대로 구축되어야 한다. 이를 위해 국가 및 학교에서 컴퓨터 및 스마트 기기 확보 및 노후화된 기자재 폐기처분 및 최신화 기기 도입, 인터넷 환경 구축, 한 번에 다수의 인원을 수용할 수 있는 서버 구축 및 점검, 시스템 전담 관리자 수용, 평가 시스템을 활용할 수 있는 교사 및 학생 역량 개발을 위한 교육 실시 등이 제안된다. 또한 온라인 총괄평가 문항 캡처 등으로 인한 문항 유출과 인터넷 검색 등으로 인한 공정성 문제에서도 혼란을 야기하지 않도록 방안을 모색해야 한다.

마지막으로, 온라인 총괄평가 시스템 개발을 위한 연구 및 실행은 시스템이 지나치게 현실을 반영하여 이론을 무시하거나 이상적인 이론에만 치우쳐 현실의 요구를 반영하지 못하는 양 극단에서의 상황이 발생하지 않도록 균형 있는 개발 방안이 모색되어야 한다. 이를 위해 추후 온라인 총괄평가 시스템에 대한 교사 및 학생 요구도를 함께 조사하여 분석한다면 더욱 발전된 형태의 온라인 총괄평가 시스템을 구현하는 데 도움이 될 것으로 기대된다.

\section{5. 감사의 글}

This work was supported by the National Research Foundation of Korea(NRF) grant funded by the Korea government (No. 2021R1A2C1005426).

\section{References}

[1] Introducing the Computer-Based Test for the National Assessment of Educational Achievement: A Developmental Study for the eNAEA, Kice, (2020), RRE 2020-5

[2] http://documents.worldbank.org/curated/en/531681585957264427/pdf/Guidance-Note-on-Remote-Learning-and COVID-19.pdf, May 25 (2020)

[3] A Study on Designing for the Computer-based NAEA, Kice (2020), RRE 2020-3

[4] P. P. Freddolion, A general model for evaluating distance education programs, Proceedings of the Annual Conference on Distance Teaching and Learning, (1997), August 6-8; Madison, Wisconsin.

[5] A study on the online evaluation system based on individually customized education, Keris, (2018), RR 2018-1

[6] C. V. Bunderson, D. K. Inouye, J. B. Olsen, The four generations of computerized educational measurement, ETS Research Report Series, (1988), Vol. 1988, No. 1, pp.1-148. DOI: 10.1002/j.2330-8516.1988.tb00291.x

[7] R. R. Meijer, M. L. Nering, Computerized adaptive testing: Overview and introduction, Applied psychological measurement, (1999), Vol.23, No.3, pp.187-194, DOI: 10.1177/01466219922031310

[8] Kija Sa, Comparison of Ability Estimates according to Test Delivery Mode and Testing Model in PPT, CFT, and CAT, Journal of Educational Evaluation, (2004), Vol.17, No.1, pp.53-78, UCI: G704-000051.2004.17.1.008

[9] Jaeyool Boo, Comparability Study of Computerized and Paper and Pencil Versions of a Summative Test in a University Course, Korean Society for Educational Evaluation, (2008), Vol.21, No1, pp.175-199, UCI : G704000051.2008 .21 .1 .001

[10] Seokho Lee, Changsu Kim, Hyeonsuk Hwang, Design and Implementation of Virtual Tutoring Estimation System on the Internet Environment, The journal of multimedia information system, (1998), Vol.1, No2, pp.204-214. 